\title{
PERCEPÇÃO DE SABOR: UMA REVISÃO
}

\section{PERCEPTION OF FLAVOR: A REVIEW}

STRAPASSON, Giovanna C. ${ }^{1}$; LOPEZ, Ana C.M. ${ }^{2}$; BOSSO, Tenille²; SANTOS,

Daniele F. ; MULINARI, R.A. ; WILLE, Grace M.F.C. ${ }^{5}$; BARREIRA, Sandra W. ${ }^{3}$

1- Farmacêutica. Parte da dissertação de mestrado do Programa de Pós Graduação em Ciências Farmacêuticas-UFPR (gicstrap@ufpr.br)

2-Aluna do Curso de Farmácia - UFPR

3-Prof. ${ }^{a}$. Associada de Síntese de Fármacos, Curso de Farmácia- UFPR- orientadora

4-Prof. Adjunto de Nefrologia, Curso de Medicina-UFPR, co-orientador

5- Prof. ${ }^{a}$. Adjunto de Tecnologia de Alimentos Dietéticos e Funcionais, Curso de Farmácia-UFPR, co-orientadora

\section{RESUMO:}

A percepção de sabor é fator importante relacionado à qualidade de vida dos indivíduos. Distúrbios dessa percepção podem levar ao consumo de substâncias tóxicas ou ao consumo exagerado de substâncias que podem interferir no tratamento de doenças, como sal na hipertensão e açúcar no diabetes. Esta percepção ocorre pela união dos sentidos químicos (gosto e olfato) com as sensações táteis. As principais responsáveis são as papilas gustativas, presentes nos órgãos de entrada no sistema digestório. Esta sensação é variável de acordo com o estado psicológico e cultural do indivíduo e tem grande importância no desenvolvimento e determinação da qualidade de produtos alimentícios. Esse artigo busca reunir conhecimentos atuais sobre a percepção de sabor e limiar de percepção.

Palavras-chave: Desenvolvimento de produto. Paladar. Percepção. Fisiologia do sabor. Análise Sensorial

\section{ABSTRACT:}

The perception of taste is an important factor related to quality of life of people. Disorders of this perception can lead to consumption of toxic substances or excessive consumption of substances which may interfere in the treatment of diseases such as hypertension and diabetes. This perception is the sum of the chemical senses (taste and smell) and tactile sensations. The main sponsors are the taste buds, which are localized at the entrance of digestive system. This sensation is variable according to the psychological and cultural development of individuals and has great importance in the 
development and determination of the quality of food. The objective of this work is gather knowledge about perception of taste and perception threshold.

Keywords: Product development. Taste. Perception. Physiology of taste. Sensory analysis

O sabor é considerado como uma experiência mista, mas unitária de sensações olfativas, gustativas e táteis percebidas durante a degustação. É baseado na detecção de produtos químicos por células especializadas, sendo percebido, principalmente, através dos sentidos do gosto e olfato, também influenciado pelos efeitos táteis, térmicos e dolorosos (HECKMANN, 2003; IAL, 2005; DUTCOSKY, 2007).

\section{FISIOLOGIA DAPERCEPÇÃO DE SABOR}

Na boca, a língua é o maior órgão sensório e está recoberta por uma membrana cuja superfície contém as papilas (FIGURA 1), onde se localizam as células gustativas ou botões gustativos, e os corpúsculos de Krause, com as sensações táteis. Porém, existem diversas áreas de acessórios localizadas no palato mole, faringe, epiglote, e terço superior do esôfago. A percepção de sabor é principalmente função das papilas gustativas, mas sabe-se que o odor também contribui fortemente com ela. Além destes, a textura dos alimentos, detectada pelo sentido tátil da boca, e a presença de substâncias que estimulam as terminações nervosas (como pimenta), podem alterar significativamente esta experiência (CULLEN, 1999; IAL, 2005; GUYTON, 2006; BATISTA, 2007, MONTEIRO, 2009).

FIGURA1 - LOCALIZAÇÃO DAS PAPILAS E INERVAÇÃO CORRESPONDENTE

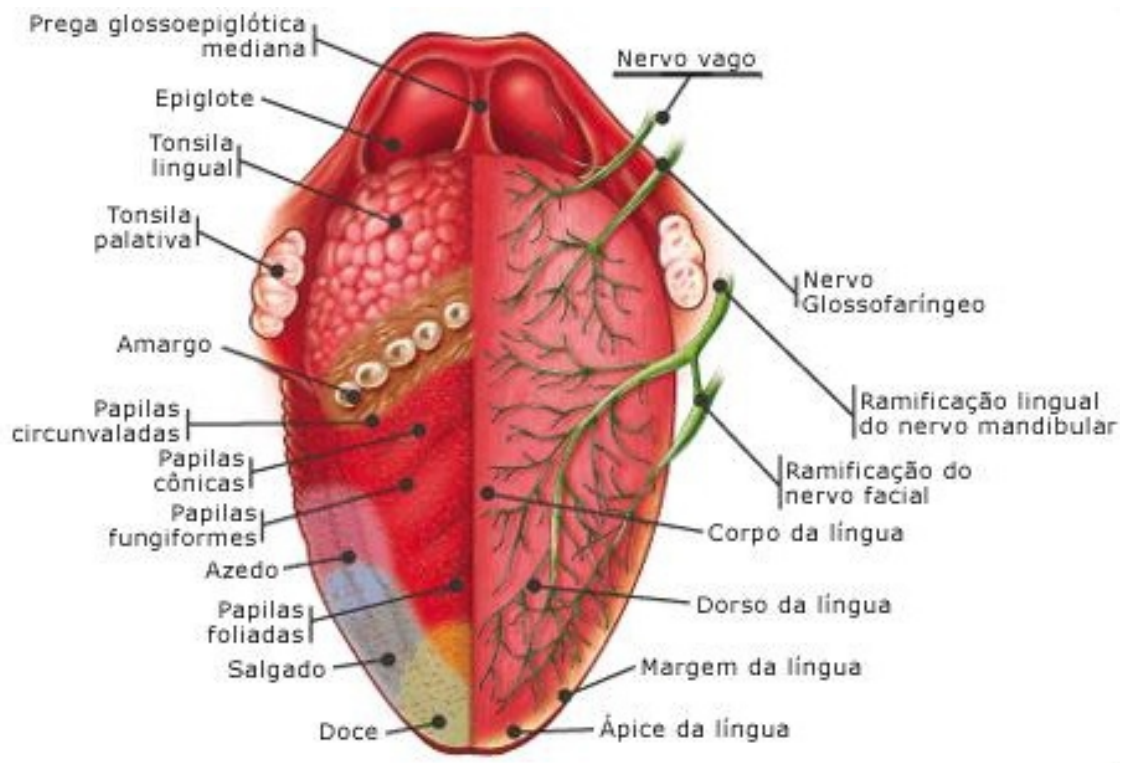

Fonte: http://www.wallstreetfitness.com.br 
O sentido gustativo e o olfativo são químicos, pois seus receptores são quimicamente estimulados. Ambos são estimulados por componentes dos alimentos, os gustativos por substâncias químicas e os olfativos por compostos voláteis. Assim, trabalham juntos na percepção dos sabores através da combinação das informações obtidas pela língua e pelo nariz, em seus respectivos centros no cérebro. Oliveira (2009) afirma que as sensações gustativas, além da língua, ocorrem por estímulos de quimiorreceptores presentes na faringe, laringe, palato mole e amídalas (IAL, 2005; GUYTON, 2006; BATISTA, 2007; MONTEIRO, 2009).

As papilas são estruturas sobressalentes, organizadas de forma colunar concêntrica, com uma aparência microscópica semelhante a uma tulipa. Essas células formam um poro, com projetos de micro vilosidades apicais que se direcionam em direção à luz do deste poro, que, por sua vez, se abrem para o epitélio da mucosa circundante (FIGURA 2). Estas estruturas emergem na superfície da mucosa da cavidade oral, onde o contato com a saliva é grande, havendo maior probabilidade da dissolução das partículas dos alimentos. Segundo Araújo (2003), para ser possível a percepção do gosto de uma substância, ela precisa ser dissolvida e difundida através do poro gustativo entorno das micro vilosidades. Portanto, quanto mais solúveis e difusíveis, maior o grau de percepção, já que desta forma elas se difundem pelos poros e alcançam as células receptoras que estão conectadas, de forma única ou conjunta, a uma fibra nervosa que transmite a sensação ao cérebro. Para exemplificar, tem-se que: substâncias muitos solúveis como o sal e o açúcar fornecem graus gustativos mais altos que substâncias pouco solúveis, como as proteínas, sendo que as substâncias insolúveis na saliva não fornecem nenhum paladar (CULLEN, 1999; COELHO, 2005; IAL, 2005; NISHIJO, 2005).

FIGURA 2 - ESTRUTURAS DE UMA PAPILA LINGUAL

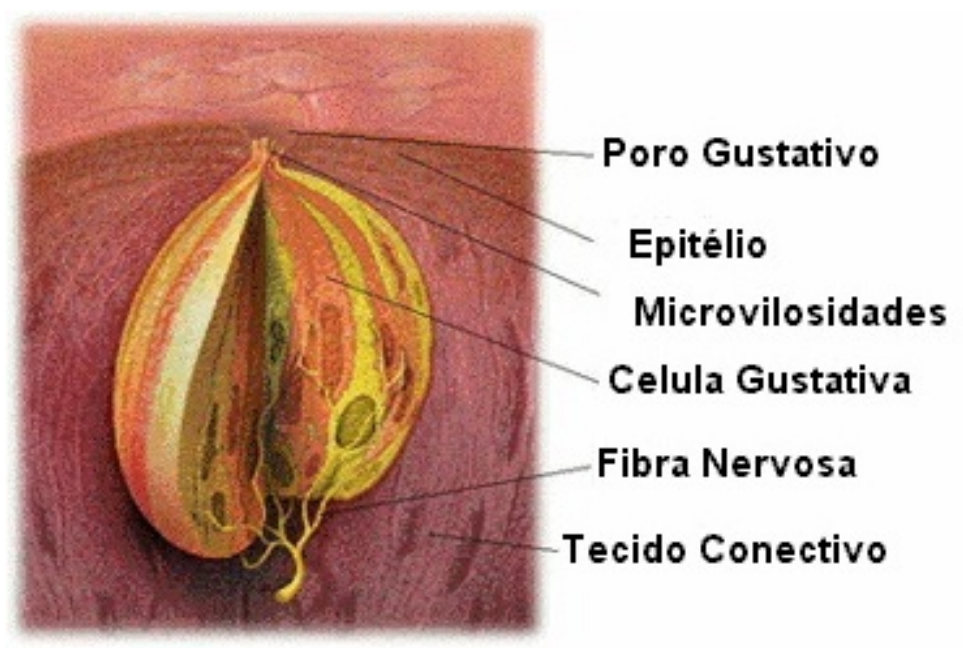

FONTE: http://www.saboreserumos.com.br 
Tais papilas adotam diferentes formas:

- Filiformes - aspectos de fibras ou fios que se estendem desde a superfície da língua em locais que os receptores gustativos são inexistentes.

- Fungiformes - apresentam forma de fungo e possuem uma grande superfície de contato, além de conterem receptores dos gostos na proporção de 8 a 10 corpúsculos gustativos por papila. Distribui-se na porção dorsal da língua, principalmente nas extremidades.

- Foliadas - apresentam forma de folhas e são encontradas na borda da língua, principalmente posterior e apresentam de 25 a 30 corpúsculos gustativos por papila. Às vezes apresenta na sua base uma pequena glândula de saliva, facilitando o acesso das substâncias gustativas.

- Circunvaladas - São as de maior tamanho (até 2,5 mm de diâmetro) e apresentam mais de 300 corpúsculos por papila, rodeadas por uma fenda na qual se acumula saliva e são localizadas no dorso da língua, formando um "v" de vértice posterior. Representam o tipo mais relevante de papila gustativa (COELHO, 2005).

As papilas gustativas possuem um determinado grau de sensibilidade para cada uma das sensações gustativas primárias: doce, azedo, salgado, amargo, metálico e umami - incluído recentemente como a quinta sensação básica, além de atuar como realçador do sabor do alimento. Isso ocorre porque o cérebro detecta o tipo de gosto pela estimulação entre as diferentes papilas gustativas. Deste modo, se uma papila que detecta principalmente a salinidade é estimulada com maior intensidade do que as outras, a sensação é interpretada como sendo de salinidade, embora as demais papilas tenham sido estimuladas (COELHO, 2005; BATISTA, 2007; DUTCOSKY, 2007).

A localização na língua onde cada gosto é predominantemente reconhecido é amplamente citada em artigos, sendo que o estudo de Woods (1998), citado em Coelho (2005), o coloca da seguinte maneira: o doce é predominantemente reconhecido na ponta, azedo e salgado nas laterais e o amargo na parte superior da língua. Porém, atualmente acredita-se que a sensibilidade a cada gosto é distribuída igualmente pela superfície da língua (DUTCOSKY, 2007).

Segundo Guyton (2006), o sabor azedo é causado por ácidos (concentração de íons hidrogênio), e sua intensidade é aproximadamente proporcional ao logaritmo da concentração hidrogeniônica. O sabor salgado é estimulado por sais ionizados, principalmente por íons de sódio (principalmente os cátions). A qualidade do sabor varia de um tipo de sal para outro, porque alguns sais podem causar outras sensações de sabor, além da salgada. O sabor doce é causado por diversas classes de produtos químicos, sendo na sua grande maioria orgânicas, dentre eles: açúcares, glicóis, álcoois, aldeídos, cetonas, amidas, ésteres, alguns aminoácidos, algumas pequenas proteínas, ácidos sulfônicos, ácidos halogenados e sais inorgânicos de chumbo e 
berílio. É particularmente interessante que leves mudanças na estrutura química, como a adição de um radical simples pode mudar a sensação de doce para amargo. O gosto amargo, como o gosto doce, não é causado por um único tipo de agente químico, mas sim pela maioria das substâncias orgânicas. Existem duas classes de substâncias especialmente capazes de causar estas sensações: as substâncias orgânicas de cadeia longa que contêm nitrogênio, e os alcalóides, que por sua vez incluem muitas drogas utilizadas em medicamentos, tais como a quinina, cafeína, estriquinina e nicotina. O chamado sabor umami, palavra japonesa que significa "delicioso", designa uma sensação de sabor agradável e é qualitativamente diferente do azedo, salgado, doce, ou amargo. É o sabor de alimentos que contem L-glutamato, tais como extratos de carne, e alguns fisiologistas consideram como uma quinta categoria dos sabores primários, e pode estar relacionado com os receptores do glutamato. No entanto, os mecanismos responsáveis por este sabor são incertos. O espectro de sabores também inclui a presença de gostos secundários (alcalino e metálico) e os elementos sensíveis à química comum (adstringente, refrescante, ardente, quente e frio). As sensações denominadas "picantes" também definidas como "ardentes" ou "pungentes", não são consideradas estímulos puros, pois são percebidos em toda a língua e garganta (IAL, 2005).

Assim, o sabor é o indicador básico da energia dos alimentos. Sua percepção é a decodificação de um estímulo registrado no cérebro através de mecanismos sensoriais. De acordo com Serrano (2002), em IOP (2008), o processo perceptivo inicia-se com a captação, através dos órgãos dos sentidos, de um estímulo que em seguida é enviado ao cérebro. Este processo pode ser dividido em duas etapas:

a) sensação: mecanismo fisiológico através do qual os órgãos dos sentidos registram e transmitem os estímulos externos;

b) interpretação: fase em que o cérebro decodifica e organiza os estímulos, dando significado a eles.

A percepção é, portanto, um processo dinâmico pelo qual aquele que percebe atribui um significado ao estímulo percebido. O processo perceptivo é subjetivo, seletivo, simplificador, limitado no tempo e cumulativo. A sua importância reside no fato de que permite que uma pessoa escolha alimentos de acordo com a sua preferência ou até de acordo com necessidades metabólicas específicas. A subjetividade refere-se à maneira individual da realidade criada pelo consumidor perante determinado produto, podendo haver discrepância entre o estímulo emitido pelo ambiente e aquele percebido pelo indivíduo (viés perceptual). O modo como cada indivíduo percebe determinado alimento influencia sua resposta ao mesmo. A percepção das características de um alimento é afetada por muitos fatores individuais, que incluem atributos sensoriais que interagem com fatores psicológicos, comportamentais e cognitivos dos consumidores. 
O contexto e a experiência são dois fatores que também afetam esta interação. Como exemplo, sabe-se que enquanto os alimentos doces são geralmente apreciados, os alimentos amargos, condimentados ou ácidos tendem a ter melhor aceitação dos adultos do que de crianças. Os alimentos com elevada densidade energética que combinam açúcar e gordura são os mais palatáveis e são prontamente aceitos sem restrições de idade, cultura e região (GUYTON, 2006, BATISTA, 2007; IOP, 2008).

Assim, variáveis intrínsecas e extrínsecas interagem entre si formando a percepção global em relação ao alimento. A percepção das variáveis intrínsecas é influenciada pelo estado de saúde dos indivíduos. A percepção do sabor dos alimentos varia dependentemente do fluxo salivar, da composição proteica da saliva, $\mathrm{pH}$, do número de botões gustativos, entre outros. Já a percepção das variáveis extrínsecas é mais complexa e depende de fatores psicológicos, ambientais, culturais e do nível educacional (IOP, 2008).

\section{LIMIARES DE PERCEPÇÃO DE SABOR}

Quando o sistema gustativo está sob avaliação, os fatores principais em estudo costumam ser o limiar para que determinado estímulo seja percebido, a caracterização de cada um dos quatro tipos de sensações gustativas (SG) fundamentais (ácido, azedo, doce, salgado e amargo) e a impressão hedônica global do estímulo (HENRIQUES, 2000).

A detecção do limiar de percepção dos sabores doce e salgado é feita segundo a norma técnica 12908 da ABNT (1993) e é de grande importância na indústria alimentícia.

Por meio desta determinação é possível fabricar alimentos modificados para determinados grupos populacionais, como diabéticos e hipertensos, que devem reduzir a ingestão de açúcar e cloreto de sódio na dieta respectivamente, utilizando o mínimo possível do elemento indesejado.

O limiar de percepção do sabor azedo do ácido clorídrico é em média de 0,0009 $\mathrm{N}$; para o sabor salgado do cloreto de sódio, 0,01 M; para o doce da sacarose, 0,01 M; e para o amargo da quinina, 0,000008 M. Nota-se que o sabor amargo é o de maior percepção (menor limiar) dentre todos, o que seria esperado, pois essa sensação prevê uma importante função protetora contra toxinas perigosas em alimentos (GUYTON, 2006).

No quadro 1 são apresentados índices relativos (recíprocos dos limiares de sabor) de diferentes substâncias. As intensidades de quatro das principais sensações do paladar são designadas, respectivamente, para as intensidades do sabor de ácido clorídrico, quinino, sacarose, e cloreto de sódio, sendo cada uma delas arbitrariamente 
escolhida para ter um sabor índice de 1. (GUYTON,2006)

QUADRO 1 - ÍNDICES RELATIVOS DE PERCEPÇÃO DE SABOR DE DIFERENTES SUBSTÂNCIAS

\begin{tabular}{|c|c|c|c|c|c|}
\hline & Substância & Índice & & Substância & Índice \\
\hline \multirow{11}{*}{ 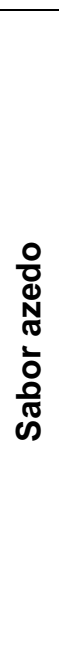 } & Ácido clorídrico & 1 & \multirow{11}{*}{$\begin{array}{l}\circ \\
\frac{0}{\pi} \\
\frac{5}{5} \\
\frac{\pi}{0} \\
\frac{0}{\pi} \\
\text { c) }\end{array}$} & Quinina & 1 \\
\hline & Ácido fórmico & 1,1 & & Brucina & 11 \\
\hline & Ácido cloro acético & 0,9 & & Estriquinina & 3,1 \\
\hline & Ácido aceto-acético & 0,85 & & Nicotina & 1,3 \\
\hline & Ácido lático & 0,85 & & Fenil-tioureia & 0,9 \\
\hline & Ácido tartárico & 0,7 & & Cafeína & 0,4 \\
\hline & Ácido málico & 0,6 & & Veratrine & 0,2 \\
\hline & Tartarato ácido de potássio & 0,58 & & Pilocarpina & 0,16 \\
\hline & Ácido acético & 0,55 & & Atropina & 0,13 \\
\hline & Ácido cítrico & 0,46 & & Cocaína & 0,02 \\
\hline & Ácido carbônico & 0,06 & & Morfina & 0,02 \\
\hline \multirow{10}{*}{ 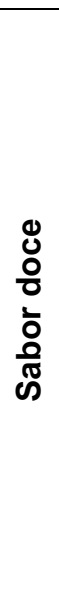 } & Sucrose & 1 & \multirow{10}{*}{ 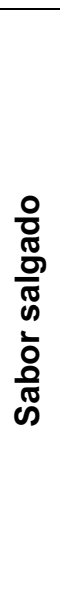 } & $\mathrm{NaCl}$ & 1 \\
\hline & 1-propoxi-2-amino-4-nitrobenzeno & 5000 & & $\mathrm{NaF}$ & 2 \\
\hline & Sacarina & 675 & & $\mathrm{CaCl}_{2}$ & 1 \\
\hline & Clorofórmio & 40 & & $\mathrm{NaBr}$ & 0,4 \\
\hline & Frutose & 1,7 & & $\mathrm{Nal}$ & 0,35 \\
\hline & Alanina & 1,3 & & $\mathrm{LiCl}$ & 0,4 \\
\hline & Glucose & 0,8 & & $\mathrm{NH}_{4} \mathrm{Cl}$ & 2,5 \\
\hline & Maltose & 0,45 & & $\mathrm{KCl}$ & 0,6 \\
\hline & Galactose & 0,32 & & & \\
\hline & Lactose & 0,3 & & & \\
\hline
\end{tabular}

FONTE: GUYTON,2006

A análise sensorial é realizada em função das respostas transmitidas pelos indivíduos às várias sensações que se originam de reações fisiológicas e são resultantes de certos estímulos, gerando a interpretação das propriedades intrínsecas dos produtos. Segundo a norma 12908 publicada pela ABNT em 1993, a análise sensorial pode ser definida como uma disciplina científica usada para analisar, medir e interpretar reações características dos alimentos e dos materiais como são percebidas pelos órgãos da visão, olfato, tato, audição e gustação. Segundo Moraes (1993), os métodos sensoriais são baseados em resposta aos estímulos que são levados por impulsos nervosos ao cérebro, que interpreta as sensações, cujas dimensões são intensidade, extensão, duração, qualidade e gosto ou desgosto em relação ao produto avaliado (IAL, 2005; MONTEIRO, 2009). 
Assim, a escolha do método de análise sensorial se torna um importante ponto para o desenvolvimento de produtos, e está baseada na resposta de questões fundamentais como: se o produto é aceito pelos consumidores; se existe diferença perceptível entre o produto em estudo e algum convencional similar; e quais os pontos de diferença. (DUTCOSKY,1996).

$\mathrm{Na}$ avaliação sensorial dos alimentos, estes são rejeitados ou aceitos de acordo com as sensações sentidas pelo homem ao observá-los, e a medida da qualidade é diretamente proporcional à reação do consumidor(PAIVA, 2005).

\section{CONCLUSÃO}

Conhecer como se processa a percepção de sabores e outros atributos dos alimentos nos permite prever reações a novos alimentos e às modificações de alimentos conhecidos, visando à melhoria da saúde dos indivíduos.

\section{REFERÊNCIAS}

Associação Brasileira de Normas Técnicas. NBR 12806: Análise Sensorial dos Alimentos e Bebidas - terminologia. Rio de Janeiro, 1993.

Associação Brasileira de Normas Técnicas. NBR 12904: Métodos de análise sensorial dos alimentos - Classificação. Rio de Janeiro, 1993.

ARAÚJO, I. E. Representações gustativas no córtex humano, e o controle central do apetite. Revista Brasileira de Psiquiatria. Rio de Janeiro, v. 25 n. S2, p. 25-28, 2003.

BATISTA,S. Influência do índice glicêmico do alimento na Palatabilidade e saciedade: um estudo com mulheres Saudáveis e diabéticas. $172 \mathrm{f}$. Tese (Doutorado em Ciência dos Alimentos) - Universidade Federal de Santa Catarina. 2007.

COELHO,H. Avaliação dos limiares de detecção dos gostos doce, salgado, ácido e amargo em pré-escolares e escolares. 130 f. Tese (Doutorado em Saúde Pública) Faculdade de Saúde Pública da Universidade de São Paulo. São Paulo, 2005.

CULLEN,M.; LEOPOLD,D. Disorders of smell and taste. Otolaryngology for the Internist. v. 83, n. 1, jan., p. 57-74, 1999. 
DUTCOSKY,S. Análise Sensorial de Alimentos. Curitiba: Ed. Champagnat,1996.

DUTCOSKY,S. Análise Sensorial de Alimentos. 2. ed. Curitiba: Ed. Champagnat, 2007.

GUYTON, A; HALL, J. Textbook of Medical Physiology. 11. ed. Philadelphia: Elsevier Inc., 2006.

HECKMANN, J. et al. Neurological Aspects of Taste Disorders. Archives of Neurology, USA, v. 60, may, p. 667-671, 2003.

HENRIQUES, A. et al. Implicações do fumo na gustação e na olfação - revisando o tema. Revista Brasileira de Otorrinolaringologia. São Paulo. v. 66, n. 5, set/out, p. 521-526, 2000 .

Instituto Adolfo Lutz. Métodos físico-químicos para análise de alimentos, 4. ed. / 1. ed. digital - São Paulo: Instituto Adolfo Lutz, 2008.

IOP,F. Percepção de alimentos por consumidores diabéticos, 160 f. Tese (doutorado em Ciência dos Alimentos) Universidade Federal de Santa Catarina. Florianópolis: 2008.

MONTEIRO,M. Percepção sensorial dos alimentos em idosos, Revista Espaço para a Saúde, Londrina, v. 10, n. 2, p. 34-42, jun., 2009.

MORAES, M. A C. Métodos para avaliação sensorial dos alimentos. 8 ed. Campinas: UNICAMP, 93 p., 1993.

NISHIJO,H.; UWANO,T.; ONO,T. Representation of Taste Stimuli in the Brain. Chemical Senses, Oxford, v.30, n. 1, p. i174-75, 2005.

Oliveira (2009)

PAIVA,E. Análise sensorial dos cafés especiais do estado de minas gerais. $65 f$. Dissertação (Programa de Pós-Graduação Strictu Sensu em Ciência dos Alimentos) Universidade Federal de Lavras, Lavras, 2005. 